\title{
Mixed Solitary Papilloma Presenting as a Cavitary Lung Lesion
}

\author{
Rodríguez Gómez Carmen María*, Foschini Martínez Giovanna, Rubio Garay Matilde and Baldó \\ Padró Xavier
}

Department of Thoracic Surgery, Hospital Universitario Dr. J Trueta de Girona, Spain

*Corresponding author: Carmen M Rodríguez Gómez, Department of Thoracic Surgery, Avenida França, s.n, CP: 17007 GIRONA, Spain

\section{ARTICLE INFO} \\ Received: 幽 February 15, 2021 \\ Published: 幽 February 24, 2021 \\ Citation: Rodríguez Gómez Carmen María, \\ Foschini Martínez Giovanna, Rubio Garay \\ Matilde, Baldó Padró Xavier. Mixed Solitary \\ Papilloma Presenting as a Cavitary Lung \\ Lesion. Biomed J Sci \& Tech Res 34(2)-
}

\section{ABSTRACT}

Abbreviations: HPV: Human Papillomavirus; CT: Computed Tomography; PET: Positron Emission Tomography; NSCLC: Non-Small Cell Lung Cancer; 2021. BJSTR. MS.ID.005514.

\section{Introduction}

Papillomas in respiratory system are very rare epithelial lesions that are classified based on number, location or histology. Multiple papillomas in the upper airway (papillomatosis) are more commonly found in the larynx of children and young adults, and in up to $30 \%$ of cases it can spread along the tracheobronchial tree being the human papillomavirus (HPV) infection de most common etiology [1-3]. However, in the absence of HPV infection, pulmonary papilloma is a rare incidental diagnosis that affects usually asymptomatic male smokers between the fifth and sixth decades of life [4-6]. Solitary nodular papilloma of the lung is very rare $(<1 \%$ of cases), with the capability of malignant degeneration towards a well differentiated squamous cell carcinoma (3). However, no cases have been described of spontaneous pulmonary cavitation, in the absence of respiratory infection. Histological subtypes are squamous, glandular and mixed. The mixed subtype is the least common with only 30 cases described in the entire scientific literature [1]; from which 19 have been reported in the Japanese bibliography [2]. We describe an exceptional case of mixed solitary papilloma of the lung presenting as a cavitary lesion in an asymptomatic patient.

\section{Clinical Case}

A 55-year-old smoker man with no history of respiratory symptoms in whom, after a traffic collision, a computed tomography (CT) was performed exposing two rib fractures and a solid, well defined, lung nodule in the upper left lobe of $17 \times 15 \times 25 \mathrm{~mm}$ (Figure 1A). After 2 month follow-up the lesion showed slight increase size and cavitation, so percutaneous lung needle biopsy was performed presenting tiny fragments of squamous epithelium interspersed with mucinous glands. Results were suggestive but inconclusive of Mucoepidermoid carcinoma. Positron emission tomography (PET-CT) described a solid, cyst-like and spiculated node in the left upper lobe of $30 \times 18 \mathrm{~mm}$ with pathological metabolism (SUV max 7.3gr / $\mathrm{ml}$ ) (Figures 1B \& 1C). Blood test, pulmonary function test and bronchoscopy were normal. The case was discussed in a multidisciplinary committee of lung cancer where surgery was recommended.

A wedge resection video-assisted surgery was performed with margins greater than $2.5 \mathrm{~cm}$. Intraoperative pathological result showed lung papilloma; therefore, further resection 
was not necessary and postoperative recovery follow without complications. The final histological results described mixed squamous and glandular cell papilloma, consisting of fibrovascular axes covered by squamous epithelium and mucinous columnar cells on the surface and ciliary cells in focal areas. No atypia or necrosis was found (Figure 1D). After 18 months of follow-up with periodic CT scans patient remains without recurrence (Figure 1).

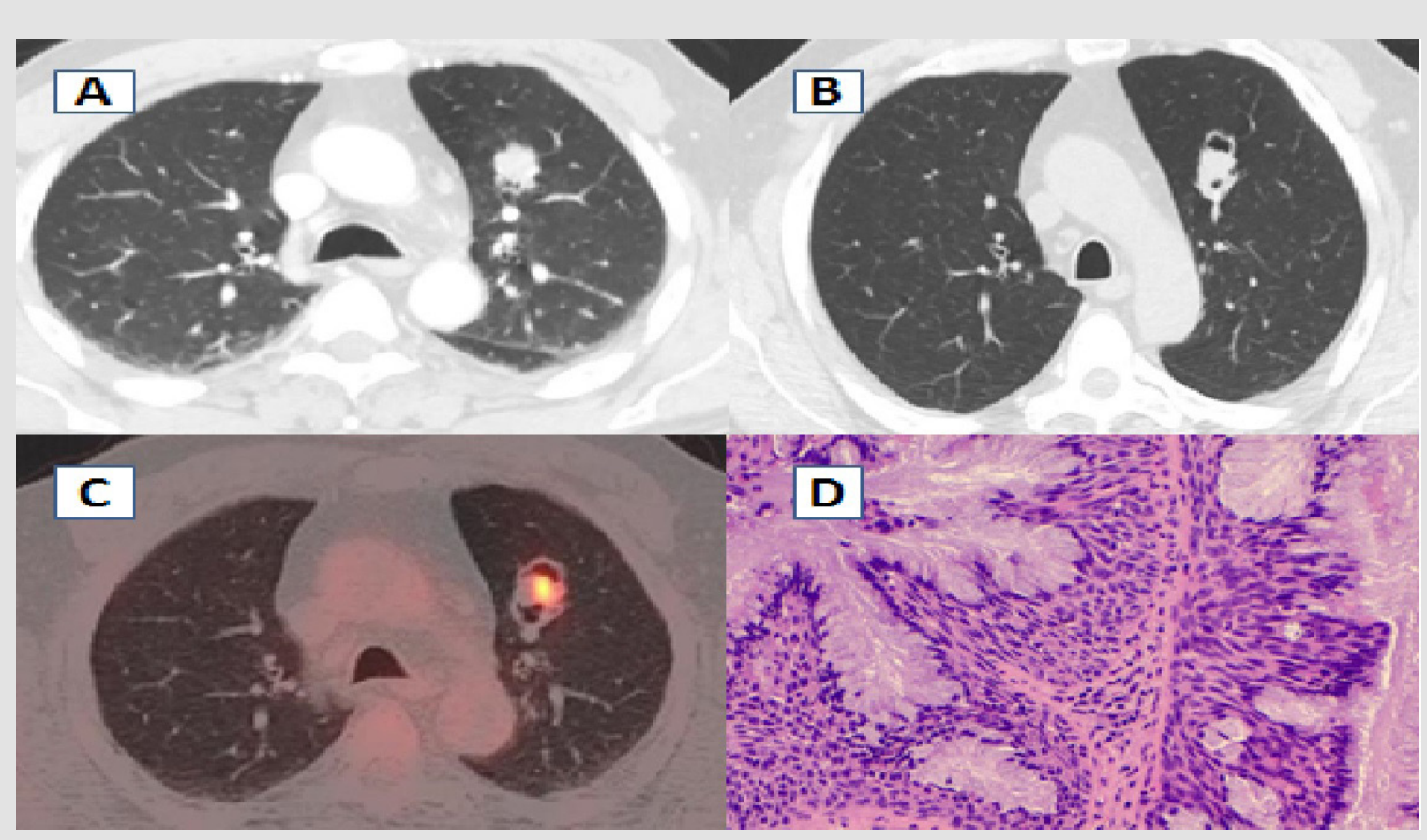

Figure 1.

\section{Discussion}

In 1998 Flieder [6-8] described solitary papilloma in the respiratory system as a rare benign lesion, accounting for less than $0.5 \%$ of all tumors in this location. But even more exceptional is its peripheral location in the lung parenchyma. The World Health Organization differentiates three histological subtypes of pulmonary papilloma: squamous, glandular and mixed. The squamous type is the most frequent one and its potential for malignancy ranges from $8 \%$ to $40 \%$ of cases according to the series [9], being enhanced by the carcinogenic effect of tobacco and HPV 16 and 18 serotypes [10]. Back in 1979, Syrjanen [7] described that HPV was associated with non-small cell lung cancer (NSCLC), but it was not until 2003 that Márquez Medina [8] refers for the first time to the possibility that HPV infection is more frequent in patients with an EGFR mutation and sensitivity to erlotinib. Glandular subtype generally affects older patients, without association to tobacco, usually found in peripheral location and no malignant transformation has been described [5]. The mixed histological subtype is the most unknown variant, with few references in literature [1] and whose etiology, clinical and pathological characteristics remain uncertain [2]. This case is a novelty finding because until now, a case of spontaneous cavitation on a pulmonary papilloma, in the absence of respiratory infection has not been described in any subtype. Clinical presentation depends on location.
In larynx, trachea, or main bronchi, most common symptoms are cough, atelectasis, infection, hemoptysis or dyspnea. Peripheral lesions in lung parenchyma are usually asymptomatic, therefor an incidental finding [4]. In terms diagnosis, the entity does not have a characteristic image, so CT scan does not allow differentiation from other intrapulmonary lesions. Likewise, it does not have specific immunohistochemical markers, making preoperative biopsy by bronchoscopy or transthoracic puncture, inaccurate for diagnosis [1]. Positrons emission tomography (PET) is not indicated due to high rate of false positives, great variability in metabolic behavior and cost [11]. Treatment of choice is surgical resection combined with antivirals in case of HPV infection [12]. Endobronchial lesions are generally resected with laser. Pulmonary lesions require surgical resection that will depend on the size, location and preoperative suspected diagnosis. Given its low local recurrence, resection must be done trying to preserve as much parenchyma as possible [2].

\section{Conclusion}

We present the first case described in the scientific literature of mixed solitary papilloma presenting as a cavitary lung lesion. It is a highly exceptional benign epithelial neoplasm that supposes a medical challenge because its radiological and pathological findings are no specific to determine the differential diagnosis with other types of lung lesions. Treatment of choice is lung resection, with good prognosis. 


\section{Funding}

No external financing has been needed for this study.

\section{Conflict of Interest}

No conflicts of interest for the specific case report.

\section{References}

1. Fei Li, Ming He, Fang Li, Yong Li, Yuan Song (2019) Histologic characteristic and prognosis of lung mixed squamous cell and glandular papillom: Sin case reports. Int J Clin Exp Pathol 12(9): 3542- 3548.

2. Yoshihito Iijima, Yuki Nakalima, Hiroyasu Akiyama, Yu Nishimura, Tomomi Hirata (2020) Mixed squamous cell and glandular papiloma of the lung. A case report and literatura review in Japan. International Journal of Surgery Case Reports 68: 39-42.

3. D Jimenez Castro, G Díaz Nuevo y, E Perez Rodriguez (1999) Tracheal and pulmonary papillomatosis. Arch Bronconeumol 35(6): 299.

4. Kaseda k, Horio H, Harada M, Hishima T (2014) Solitary glandular papillomaof the peripheral lun: Acase report os two cases. World JsURG Oncolo 12: 149.

5. Bayarri Lara C, Moyano Rodriguez MJ, Torres Bermudez JR, Ruiz Zafra F] (2019) Surgical Resection of endobronchial Glandular Papilloma. Arch Bronconeumol 55(5): 268-281.

\section{ISSN: 2574-1241}

DOI: 10.26717/BJSTR.2021.34.005514

Rodríguez Gómez Carmen María. Biomed J Sci \& Tech Res

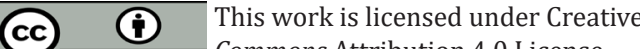

Submission Link: https://biomedres.us/submit-manuscript.php
6. Flieder DB, Koss MN, Nicholson A, Sesterhenn IA, Petras RE, et al. (1998) Solitary pulmonary papillomas in adults: A clinicopathologic and in situ hybridization study of 14 cases combined with 27 cases in the literatura. Am J Surg Pathol 22: 1328-1342.

7. Giuliani L, Favalli C, Syrjanen K, Ciotti M (2007) Human papillomavirus infections in lung cáncer. Detection of E6 and E7 transcripts and review of the lieterature. Anticancer Res 27(4C): 2697-2704.

8. Márquez Medina D, Gasol Cudós A, Taberner Bonastre T, Samamé PerezVargas JC, Salud Salvia, et al. (2013) Virus del papiloma humano en cáncer de pulmón no microcítico. Impacto de mutaciones del EGFR o respuesta a erlotinib. Arch Bronconeumol 49(2): 79-81.

9. Inoue Y, Oka M, Ishii H, Kimino K, Kishikawa M, et al. (2001) A solitary bronchial papiloma with malignant changes. Inter Med 40: 56-60.

10. Khoury R, Sauter S, Butsch Kovacic M, Nelson AS, Myers KC, et al. (2018) Risk of human papillomavirus infection in cáncer prone individuals: What we Know Viruses. Viruses 10: 47.

11. Yu JP, Barajas RF Jr, Olorunsola D, Sugrue LP, Hernandez Pampaloni M (2013) Heterogenesu 18 FDG uptake in recurrent respiratory papillomatosis. Clin Nucl Med 38(5): 387-389.

12. Wierzbicka M, Jackowska J, Bartochowska A, Józefiak A, Szyfter W, et al. (2011) Effectiveness of cidofovir intralesional treatment in recurrent respiratory papil-lomatosis. Eur Arch Otorhinolaryngol 268: 1305-1307.

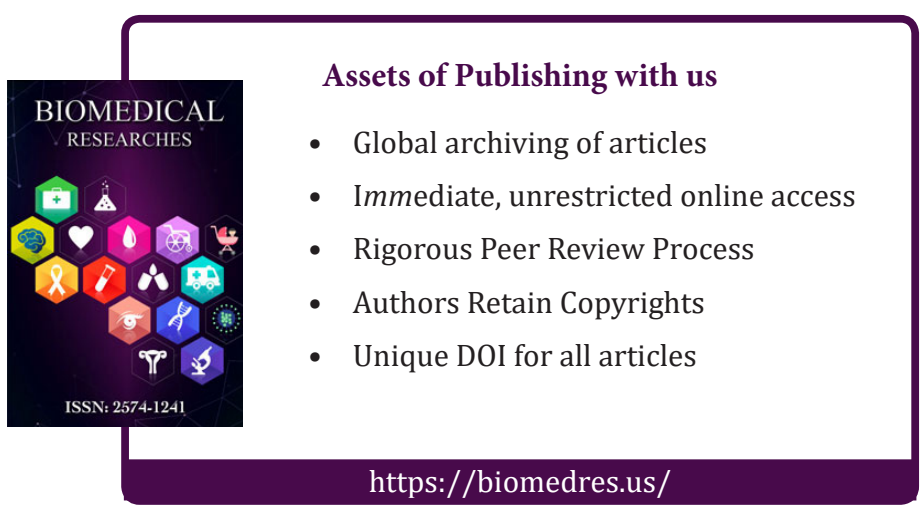

